\title{
Risk of impaired nutritional status and flare occurrence in IBD outpatients
}

\author{
Corinne E.G.M. Spooren ${ }^{\mathrm{a}, \mathrm{b}, *}$, Dion S.J. Wintjens ${ }^{\mathrm{a}, \mathrm{b}}$, Marin J. de Jong ${ }^{\mathrm{a}, \mathrm{b}}$, \\ Andrea E. van der Meulen-de Jong ${ }^{\mathrm{c}}$, Mariëlle J. Romberg-Camps ${ }^{\mathrm{d}}$, Marco C. Becx ${ }^{\mathrm{e}}$, \\ Jeroen P. Maljaars ${ }^{c}$, Ad A. van Bodegraven $^{\mathrm{d}}$, Nofel Mahmmod ${ }^{\mathrm{e}}$, Tineke Markus ${ }^{\mathrm{f}}$, \\ Wim M. Hameeteman ${ }^{a}$, Ad A.M. Masclee ${ }^{a, b}$, Bjorn Winkens ${ }^{g}$, Daisy M.A.E. Jonkers ${ }^{\mathrm{a}, \mathrm{b}}$, \\ Marie J. Pierik ${ }^{\mathrm{a}, \mathrm{b}}$ \\ a Department of Internal Medicine, Division of Gastroenterology and Hepatology, Maastricht University Medical Centre+, Maastricht, The Netherlands \\ ${ }^{\mathrm{b}}$ School for Nutrition and Translational Research in Metabolism (NUTRIM), Maastricht University Medical Centre+, Maastricht, The Netherlands \\ ${ }^{\mathrm{c}}$ Department of Gastroenterology and Hepatology, Leiden University Medical Centre, Leiden, The Netherlands \\ ${ }^{\mathrm{d}}$ Department of Gastroenterology, Geriatrics, Internal and Intensive Care Medicine (Co-MIK), Zuyderland Medical Centre, Sittard-Geleen-Heerlen, The \\ Netherlands \\ e Department of Gastroenterology and Hepatology, St. Antonius Hospital, Nieuwegein, The Netherlands \\ ${ }^{f}$ CCUVN, Dutch IBD Patients Organization, Woerden, Netherlands \\ ${ }^{g}$ Department of Methodology and Statistics, Maastricht University, Maastricht, The Netherlands
}

\section{A R T I C L E I N F O}

\section{Article history:}

Received 25 February 2019

Accepted 23 May 2019

Available online 15 June 2019

\section{Keywords:}

Crohn's disease

Nutritional status

Telemedicine

Ulcerative colitis

\begin{abstract}
A B S T R A C T
Background: Inflammatory bowel disease (IBD) patients are at risk of an impaired nutritional status. The impact thereof on the IBD relapse risk is clinically relevant, though sparsely investigated.

Aim: The aim was to explore the association between an impaired nutritional status risk and the occurrence of disease flares in IBD outpatients participating in a longitudinal telemedicine study.

Methods: IBD outpatients were recruited from the myIBDcoach study cohort, with one year clinical followup. Through myIBDcoach, a telemedicine tool, patients reported on disease activity and risk of impaired nutritional status (i.e. Short Nutritional Assessment Questionnaire $>1$ and/or BMI $<18.5 \mathrm{~kg} / \mathrm{m}^{2}$ ) every one to three months. Data was analysed by generalized estimating equation modelling.

Results: In total, 417 patients were included. During follow-up, 49 patients (11.8\%) flared after initial clinical remission and 53 patients $(12.7 \%)$ showed an increased risk of impaired nutritional status. The risk of impaired nutritional status was associated with flare occurrence (OR 2.61 (95\% CI 1.02-6.69)). Conclusions: The risk of an impaired nutritional status was associated with subsequent flares in IBD outpatients. This emphasizes the importance of monitoring disease activity in IBD patients at risk of impaired nutritional status.
\end{abstract}

(c) 2019 Editrice Gastroenterologica Italiana S.r.l. Published by Elsevier Ltd. All rights reserved.

\section{Introduction}

Inflammatory bowel disease (IBD) is a chronic inflammatory disease of the gastrointestinal tract, with Crohn's disease (CD) and ulcerative colitis (UC) as main subtypes. The disease course is characterized by a wide variation in duration and frequency of relapsing and quiescent periods between patients. Several factors have been associated with relapse risk, such as a high frequency of flares

\footnotetext{
* Corresponding author at: Division of Gastroenterology and Hepatology, Maastricht University Medical Centre+, PO Box 5800, 6202 AZ, Maastricht, The Netherlands.

E-mail address: c.spooren@maastrichtuniversity.nl (C.E.G.M. Spooren).
}

within the first year of diagnosis [1,2], poor medication adherence [3], and active smoking in CD patients [4]. However, these do not sufficiently predict the disease course. Identification of further factors contributing to the development of relapses is therefore warranted.

IBD patients are at risk of an impaired nutritional status due to disease related changes in absorption and/or requirements, often in combination with an unbalanced dietary intake [5]. Reported prevalences range from 16 to $75 \%$ in IBD patients [6-8]. The variation may be due to heterogeneity in study methods and definitions used for defining an impaired nutritional status, in many publications often referred to as malnutrition. Defining malnutrition remains challenging. Therefore, the American Society of Parenteral and Enteral Nutrition (ASPEN) recommends diagnostic characteris- 
tics to identify malnutrition in adults, by which two of the following six criteria need to be fulfilled: i.e. low energy intake, weight loss, loss of muscle mass, loss of subcutaneous fat, fluid accumulation, and handgrip strength [9]. However, validated screening tools to identify patients at risk of malnutrition, such as the Short Nutritional Assessment Questionnaire (SNAQ) and the Malnutrition Universal Screening Tool (MUST), are more often used, since these are less time consuming [10].

An impaired nutritional status may impact disease course. Malnutrition, defined by the Subjective Global Assessment, which is a nutritional assessment instrument, has been found to be related to a diminished quality of life in hospitalized patients with IBD [11]. In addition, radiologically assessed loss of muscle mass was found to be associated with an increased risk of intestinal resection and postoperative complications in IBD patients [12-15]. Furthermore, higher disease activity was associated with a lower skeletal muscle index among UC patients [13]. In previous cross-sectional and longitudinal studies, active disease was reported to affect body composition in both CD and UC patients [16-18]. However, both $\mathrm{CD}$ and UC patients with quiescent disease can also suffer from an altered body composition (i.e. fat mass and fat free mass) $[19,20]$. Furthermore, in a prior study, the nutritional status of recently diagnosed IBD patients was shown to be affected negatively in a prior study [21]. It can thus be hypothesized that an impaired nutritional status could be a risk factor for the development of disease activity. Therefore, as an explorative study, we aimed to analyse whether the risk of an impaired nutritional status was associated with flare occurrence in quiescent IBD outpatients in a longitudinal, observational study.

\section{Materials and methods}

\subsection{Study design}

For the present longitudinal study, available data from the myIBDcoach study was used in an explorative analysis. MyIBDcoach is a telemedicine tool, accessible on a secured webpage through computer, tablet or smartphone, for the monitoring of IBD patients at home [22]. In the mylBDcoach trial, the effect of disease monitoring with myIBDcoach on healthcare utilization and quality of care was investigated. All consecutive IBD patients between 18-75 years, with sufficient knowledge of the Dutch language and internet access, from two tertiary referral centres and two non-academic hospitals in the Netherlands were eligible for inclusion for this trial and randomized in the mylBDcoach or standard care group. All patients had an established diagnosis of $C D$ or UC, fulfilling the international diagnostic criteria [23].

Every single month, patients in the telemedicine arm completed monitoring modules, comprising questions on disease activity, use of medication, smoking status, weight, and malnutrition risk based on the SNAQ. If a patient achieved remission (i.e. low clinical activity for three consecutive months), patients were allowed to complete the monitoring module once every three months. The study design is described in detail elsewhere [24].

The mylBDcoach study was approved by the Medical Research Ethics Committee of the Maastricht University Medical Centre+ (NL47697.068.14) and registered at ClinicalTrials.gov (NCT02173002) and the study protocol conformed to the provisions of the declaration of Helsinki. All patients gave written informed consent prior to participation [22,24].

Patients who were randomized to the mylBDcoach intervention group were included in the present study. Baseline characteristics (e.g. height, disease phenotype, duration, and medication use) were extracted from patient files using standardized registration forms. During the 12 months of follow-up, information on weight (to determine BMI), disease activity by a symptom-based patient reported outcome measure (the Monitor IBD At Home (MIAH) questionnaire [25]), and risk for malnutrition (by the SNAQ) was obtained every one to three months.

In line with the myIBDcoach trial, disease activity (flares) were defined as clinical symptoms indicative of disease activity (i.e. positive score on the Monitor IBD At Home (MIAH) questionnaire $[25,26]$ or increased symptoms during outpatient visits) in combination with either a concurrent faecal calprotectin $>250 \mu \mathrm{g} / \mathrm{g}$, or disease activity on endoscopy, magnetic resonance imaging, or computed tomography. In daily clinical practice, in case of clinically severe symptoms suggestive of IBD disease activity, the treating physician occasionally judged these symptoms to be evident enough to adjust therapy. Therefore, to capture all flares, also symptoms indicative of disease activity resulting in dose escalation or initiation of a new drug were defined as disease activity [22]. Otherwise patients were considered to be in remission.

The SNAQ was developed as a non-invasive screening tool to assess malnutrition in both in- and outpatient settings [27,28] and comprises of three questions, i.e. unintentional weight loss over a predefined time period (depending on weight loss: 2 or 3 points), experience of decreased appetite during the last month (1 point), and/or use of supplemental drinks or tube feeding during the last month (1 point). For the present study, the risk of an impaired nutritional status was defined as a SNAQ $\geq 2$ points and/or $\mathrm{BMI}<18.5 \mathrm{~kg} / \mathrm{m}^{2}$. Both parameters were determined every one to three months.

\subsection{Statistical analysis}

Numerical variables were presented as means with corresponding standard deviation (SD) and categorical variables as numbers with percentages. Baseline characteristics were compared between groups (patients who relapse versus patients who do not relapse) by the independent samples $t$-test for numerical variables, and Chi-square test or Fisher's exact test when appropriate, for categorical variables. Generalized estimating equations model was used to identify an association between the risk of impaired nutritional status and the development of flares in the following three months. This method accounts for repeated measures within the same patient, with an unstructured covariance pattern.

At each time-point of measurement, flare status (yes/no), as well as the risk of impaired nutritional status (yes/no) was recorded. In patients with quiescent disease, the first three months were excluded from the analyses to prevent potential carry over effects of histological inflammation in clinical inactive patients at time of inclusion. When active disease was present at inclusion or during follow up, the following six months were excluded from the analyses as a wash out period, and to start the follow-up from a remissive state onwards.

For the generalized estimating equations model, all positive values on the risk of an impaired nutritional status in the three months preceding a flare were regarded as possible predictors.

Since we aimed to assess the prospective association, the risk of an impaired nutritional status measured at the same measurement moment as a flare was not considered as a predictor. Since patients were able to complete the questionnaires either every single or every three months, the flare status was determined for the subsequent three months after the risk of an impaired nutritional status was assessed. The generalized estimating equations model was adjusted for potential confounding effects of sex, disease phenotype, disease duration at inclusion, and smoking status at inclusion. Two-sided P-values $\leq 0.05$ were considered statistically significant. Statistical analysis was performed using IBM SPSS statistics for Windows, Version 22 (IBM, Armonk, NY). 
Table 1

Patient characteristics, stratified by occurrence of disease flares.

\begin{tabular}{|c|c|c|c|}
\hline & Relapsers $(n=49)$ & Non-relapsers $(n=368)$ & p-Value \\
\hline Crohn's disease n (\%) & $26(53.1)$ & $222(60.3)$ & 0.331 \\
\hline Male, n (\%) & $15(30.6)$ & $158(42.9)$ & 0.100 \\
\hline BMI $\left(\mathrm{kg} / \mathrm{m}^{2}\right)$, mean $(\mathrm{SD})$ & $25.37(4.3)$ & $25.14(4.0)$ & 0.705 \\
\hline \multicolumn{4}{|l|}{ Montreal at diagnosis ${ }^{\mathrm{a}}$} \\
\hline Age (CD \& UC) & & & 0.600 \\
\hline $\mathrm{A} 1,<17$ years, $\mathrm{n}(\%)$ & $8(16.3)$ & $60(16.3)$ & \\
\hline $\mathrm{A} 2,17-40$ years, $\mathrm{n}(\%)$ & $26(53.1)$ & $219(59.5)$ & \\
\hline$A 3,>40$ years, $n(\%)$ & $15(30.6)$ & $89(24.2)$ & \\
\hline Disease location (CD) & & & 0.741 \\
\hline L1, ileal, n (\%) & $7(26.9)$ & $73(32.9)$ & \\
\hline L2, colonic, n (\%) & $6(23.1)$ & $55(24.8)$ & \\
\hline L3, ileocolonic, n (\%) & $13(50.0)$ & $94(42.3)$ & \\
\hline Disease behaviour (CD) & & & 0.958 \\
\hline B1, non-stricturing non-penetrating, n (\%) & $16(61.5)$ & $134(60.6)$ & \\
\hline $\mathrm{B} 2$, stricturing, $\mathrm{n}(\%)$ & $7(26.9)$ & $57(25.8)$ & \\
\hline B3, penetrating, $\mathrm{n}(\%)$ & $3(11.5)$ & $30(13.6)$ & \\
\hline Disease extent (UC) & & & 0.768 \\
\hline E1, proctitis, n (\%) & $2(8.7)$ & $19(12.8)$ & \\
\hline E2, left-sided, $n(\%)$ & $10(43.5)$ & $69(46.3)$ & \\
\hline E3, pancolitis, n (\%) & $11(47.8)$ & $61(40.9)$ & \\
\hline Age at inclusion (years), mean (SD) & $46.08(15.2)$ & $43.95(13.7)$ & 0.313 \\
\hline Disease duration at inclusion (years), mean (SD) & $13.45(10.9)$ & $13.39(10.4)$ & 0.971 \\
\hline Active disease at inclusion, $\mathrm{n}(\%)$ & $4(8.2)$ & $28(7.6)$ & 0.908 \\
\hline Medication use at inclusion & & & 0.434 \\
\hline No medication/5-ASA, $\mathrm{n}(\%)$ & $15(30.6)$ & $142(39.3)$ & \\
\hline Immunomodulators, $\mathrm{n}(\%)$ & $16(32.7)$ & $93(25.8)$ & \\
\hline Biologics, n (\%) & $18(36.7)$ & $126(34.9)$ & \\
\hline Current smoking at inclusion, $\mathrm{n}(\%)$ & $1(2.0)$ & $65(17.7)$ & $0.005^{b}$ \\
\hline
\end{tabular}

$\mathrm{n}$, number of patients / SD, standard deviation / BMI, body mass index / 5-ASA, 5-aminosalicylic acid.

a According to the Montreal classification [45].

b p-Value below 0.05 .

\section{Results}

In total, 465 IBD patients were allocated to the intervention group in the myIBDcoach trial [22]. Patients who were not eligible, i.e. never started using the application, never achieved a period of remission or were lost to follow-up for other reasons were excluded from further analyses. Finally, 417 patients were included in the present study.

Baseline characteristics at inclusion, stratified by flare status during follow up, are presented in Table 1. During follow-up, 49 (11.8\%) individual patients $(C D=26, U C=23)$ experienced a flare after initial remission. Less active smokers were found among those that relapsed during follow-up compared to the 'non-relapsers' $(p=0.005)$. No other differences in baseline characteristics were found between these groups.

At inclusion, six (1.4\%) patients had a $\mathrm{BMI}<18.5 \mathrm{~kg} / \mathrm{m}^{2}, 216$ (51.8\%) patients had a BMI of $18.5-25 \mathrm{~kg} / \mathrm{m}^{2}, 147$ (35.3\%) patients had a BMI of $25-30 \mathrm{~kg} / \mathrm{m}^{2}$, and $48(11.5 \%)$ patients had a $\mathrm{BMI}>30 \mathrm{~kg} / \mathrm{m}^{2}$. In total, $53(12.7 \%)$ individual IBD patients were at risk of an impaired nutritional status based on a positive SNAQ score $(\mathrm{n}=45), \mathrm{BMI}<18.5 \mathrm{~kg} / \mathrm{m}^{2}(\mathrm{n}=5)$, or both $(\mathrm{n}=3)$ during follow-up.

In the generalized estimating equations analyses, the risk of an impaired nutritional status was found to be associated with the occurrence of a flare in the following three months (OR 2.61 (95\% CI 1.02-6.69, $\mathrm{p}=0.046)$ ). Furthermore, in this model female sex (OR $2.12(95 \% \mathrm{CI} 1.08-4.15, \mathrm{p}=0.029))$ was also identified as a risk factor for the development of a flare, while active smoking showed a negative association (OR 0.14 (95\% CI 0.02-0.97, p=0.047)) (Table 2). In the generalized estimating equations model, medication use at time of inclusion was not incorporated as confounder due to the small number of relapsing patients during follow up. When medication use at time of inclusion was added to the model, a comparable increased risk was found (OR 2.48 (95\% CI 0.96-6.41, p=0.061)), though not significant.
Table 2

Multivariable generalized estimating equations model: association between impaired nutritional status risk in IBD and disease flares.

\begin{tabular}{llll}
\hline & OR & $95 \%-C I$ & p-value \\
\hline Impaired nutritional status & 2.61 & $1.02-6.69$ & $0.046^{\mathrm{b}}$ \\
UC phenotype & 1.43 & $0.78-2.65$ & 0.251 \\
Sex, female & 2.12 & $1.08-4.15$ & $0.029^{\mathrm{b}}$ \\
Active smoker & 0.14 & $0.02-0.97$ & $0.047^{\mathrm{b}}$ \\
Disease duration $^{\mathrm{a}}$ & 1.01 & $0.98-1.04$ & 0.642 \\
\hline
\end{tabular}

OR, Odds ratio / 95\%-CI, 95\%-Confidence interval.

a At inclusion.

b p-Value below 0.05 .

\section{Discussion}

In this longitudinal study in daily practice, the risk of an impaired nutritional status, defined by a positive SNAQ or BMI $<18.5 \mathrm{~kg} / \mathrm{m}^{2}$, was found to be associated with the occurrence of a flare.

IBD patients are at risk of an impaired nutritional status due to disease related changes in absorption and/or requirements, especially during active inflammation, often in combination with an unbalanced dietary intake [5]. An impaired nutritional status is thereby a consequence of the disease, although it may also further impact disease course. Previous studies reported that a decreased skeletal muscle index increased the risk of an intestinal resection in hospitalized CD patients with an exacerbation [12], increased the need for colectomy in UC patients [13], predicted the need for rescue therapy in acute severe UC patients [29], was associated with postoperative complications [14,15], and with anti-TNF treatment failure in IBD patients [30]. An impaired nutritional status may contribute to the development of a flare or worse disease outcome by malnutrition induced changes in the immune system leading to altered GI hormone secretion (e.g. leptin), changes in immune cell populations, and/or increased intestinal permeability 
[31-34]. A mice study on the effects of fasting showed, for example, that changes in immune response occur rather early after inducing nutritional deficiencies [32]. After $48 \mathrm{~h}$, activated T cells from fasted mice showed decreased ability to secrete IL-2 and IFN-y when compared with control fed mice. A vicious circle may develop in which an impaired nutritional status and intestinal inflammation affect each other. Furthermore, malnutrition is found to affect the microbiota composition and activity, and thereby may also impact disease course [35]. To our knowledge, the current study is the first to specifically analyse the association of impaired nutritional status risk on subsequent flare occurrence. Future studies should also address potential underlying mechanisms.

In the present study, the SNAQ in combination with BMI was used as screening method for risk of an impaired nutritional status, since the SNAQ alone may lead to underreporting in an outpatient setting [36]. The SNAQ and MUST both contain questions on unintentional weight loss and food intake. In contrast to the SNAQ, a low BMI $\left(18.5-20\right.$ or $\left.<18.5 \mathrm{~kg} / \mathrm{m}^{2}\right)$ is taken into account in the MUST questionnaire. The MUST may however lead to overreporting of patients at risk in the outpatient setting [36]. Therefore, in line with one of the diagnostic criteria for malnutrition by the European Society for Clinical Nutrition and Metabolism (ESPEN) [10], only a $\mathrm{BMI}<18.5 \mathrm{~kg} / \mathrm{m}^{2}$ was added to the SNAQ to capture all patients at risk of impaired nutritional status in the current study. Fifty-three patients were at risk of an impaired nutritional status during follow up, of which the majority of the patients $(n=45)$ had a positive SNAQ in combination with a BMI $>18.5 \mathrm{~kg} / \mathrm{m}^{2}$, five patients had a $\mathrm{BMI}<18.5 \mathrm{~kg} / \mathrm{m}^{2}$ and a negative SNAQ, and three patients had both a positive SNAQ score and a BMI $<18.5 \mathrm{~kg} / \mathrm{m}^{2}$.

The overall distribution of our patients over the different weight categories (according to the World Health Organization definitions) [37] were comparable with percentages of overweight and obesity in a representative healthy population in South-Limburg, a province in the Netherlands [38]. The majority of the IBD patients in the present study had a normal BMI (51.8\%) while a significant proportion was overweight (35.3\%) or obese (11.5\%). Due to an unfavourable fat-muscle ratio, which is not necessarily reflected by BMI, it cannot be excluded that patients with a BMI $18.5-25 \mathrm{~kg} / \mathrm{m}^{2}$ do have a decreased muscle mass and are thereby at risk of impaired nutritional status.

A commonly used model for analysing the body composition is the two-compartment model in which body weight is subdivided in fat mass and fat free mass. Skeletal muscle mass represents a large proportion of the fat free mass. Prior studies reported that changes in fat free mass, are not always captured by malnutrition screening questionnaires in IBD patients $[20,39]$. This underlines the necessity in future studies to combine a malnutrition screening questionnaire with a simple, non-invasive body composition analysis, and also, to incorporate changes in fat free mass for timely identification of patients at risk. A technique which can be considered is the handgrip strength, as parameter of muscle strength [40].

In the present study, flare development was also found to be positively associated with female sex and negatively with smoking status at time of inclusion. In CD for example, smoking is found to increase the risk of a flare, whereas in UC smoking cessation is [41]. Our finding may be affected by analysis of the total IBD population. Separate analyses for CD and UC were not performed due to the limited sample size, but should be taken into account in future studies.

A major strength of the present study is the longitudinal design of the study in a relatively large, unselected outpatient study population. The study population was found to be representative for the general IBD population in the South Limburg area [22,42]. Furthermore, by the use of telemedicine, disease activity, and malnutrition screening risk were measured repeatedly and standardized. How- ever, some limitations of this study should be addressed. For the present explorative study, available data from the myIBDcoach study was used. Therefore, no sample size calculation has been performed, and we were not able to correct for all potential confounders for flare development, such as prior surgery, time since last flare, and prior smoking status. The present study shows a significant association between impaired nutritional status risk and flare occurrences in the entire IBD cohort. Separate analyses for $C D$ and UC were not performed due to a small number of patients. However, these analyses are of interest since factors influencing flare occurrence may differ between these phenotypes, and should be included in future studies. Furthermore, ongoing histological inflammation at time of inclusion and during follow up cannot be completely excluded, since disease activity was monitored by clinical parameters. However, to prevent carry over effects of histological inflammation, the first three months from patients with quiescent disease were excluded from the analyses. Finally, it should be taken into account that flares can be affected by enteral nutrition, particularly in CD [43]. However, in the present study, use of enteral nutrition was limited and was not found to impact our findings (data not shown).

The aim of the present explorative study was to investigate an association between the risk of an impaired nutritional status and flare occurrence. In clinical practice, it has already been shown that early treatment of malnourished inpatients for any disease or operation, based on screening, leads to a shorter length of hospital stay and is cost-effective [44]. Since this is the first longitudinal study analysing the association of impaired nutritional status risk on flare occurrences, our results should be confirmed in other cohorts. Larger longitudinal studies on the impact of an impaired nutritional status risk, incorporating body composition analysis and muscle strength, and taking confounders and separate analysis for CD and UC into account, are of special interest to confirm the actual effect on disease activity. Additionally, studies on timely dietary and/or physiotherapy interventions, aiming to improve nutritional status and treatment outcome are warranted.

In conclusion, in the present longitudinal observational study, we found an association between the presence of the risk of an impaired nutritional status and IBD flare occurrence. This emphasizes the importance of monitoring disease activity in IBD patients at risk of an impaired nutritional status.

\section{Conflict of interest}

None declared.

\section{Funding}

For the present study, data from the myIBDcoach study was used. The mylBDcoach trial was supported by an academic incentive fund of the Maastricht University Medical Centre+ (31962340B). MyIBDcoach was developed by Sananet BV using an unrestricted grant from Ferring.

\section{Acknowledgements}

J. Haans, M. Cilissen, H. Tomlow, E. Keulen, J. Wilbrink, L. Colautti-Duijsens, M. Verwey, N. Peek, H. Slingerland, R. Veenendaal, N. Ipenburg, M. van Kouwen, M. Somers K. Achterberg, E. Smit, M. Spruit.

\section{References}

[1] Munkholm P, Langholz E, Davidsen M, Binder V. Disease activity courses in a regional cohort of Crohn's disease patients. Scand J Gastroenterol 1995;30:699-706. 
[2] Hoie O, Wolters F, Riis L, Aamodt G, Solberg C, Bernklev T, et al. Ulcerative colitis: patient characteristics may predict 10-yr disease recurrence in a Europeanwide population-based cohort. Am J Gastroenterol 2007;102:1692-701.

[3] Feagins LA, Iqbal R, Spechler SJ. Case-control study of factors that trigger inflammatory bowel disease flares. World J Gastroenterol 2014;20:4329-34.

[4] Dutta AK, Chacko A. Influence of environmental factors on the onset and course of inflammatory bowel disease. World J Gastroenterol 2016;22:1088-100.

[5] Hartman C, Eliakim R, Shamir R. Nutritional status and nutritional therapy in inflammatory bowel diseases. World J Gastroenterol 2009;15:2570-8.

[6] Scaldaferri F, Pizzoferrato M, Lopetuso LR, Musca T, Ingravalle F, Sicignano LL, et al. Nutrition and IBD: malnutrition and/or Sarcopenia? A practical guide. Gastroenterol Res Pract 2017;2017:8646495.

[7] Casanova MJ, Chaparro M, Molina B, Merino O, Batanero R, Duenas-Sadornil C, et al. Prevalence of malnutrition and nutritional characteristics of patients with inflammatory bowel disease. J Crohns Colitis 2017;11:1430-9.

[8] Mijac DD, Jankovic GL, Jorga J, Krstic MN. Nutritional status in patients with active inflammatory bowel disease: prevalence of malnutrition and methods for routine nutritional assessment. Eur J Intern Med 2010;21:315-9.

[9] White JV, Guenter P, Jensen G, Malone A, Schofield M, Academy Malnutrition Work G, et al. Consensus statement: academy of nutrition and dietetics and American Society for parenteral and enteral nutrition: characteristics rec ommended for the identification and documentation of adult malnutrition (undernutrition). JPEN J Parenter Enteral Nutr 2012;36:275-83.

[10] Cederholm T, Barazzoni R, Austin P, Ballmer P, Biolo G, Bischoff SC, et al. ESPEN guidelines on definitions and terminology of clinical nutrition. Clin Nutr 2017;36:49-64

[11] Norman K, Kirchner H, Lochs H, Pirlich M. Malnutrition affects quality of life in gastroenterology patients. World J Gastroenterol 2006:12:3380-5.

[12] Bamba S, Sasaki M, Takaoka A, Takahashi K, Imaeda H, Nishida A, et al. Sarcopenia is a predictive factor for intestinal resection in admitted patients with Crohn's disease. PLoS One 2017;12:e0180036.

[13] Zhang T, Ding C, Xie T, Yang J, Dai X, Lv T, et al. Skeletal muscle depletion correlates with disease activity in ulcerative colitis and is reversed after colectomy. Clin Nutr 2017;36:1586-92

[14] Pedersen M, Cromwell J, Nau P. Sarcopenia is a predictor of surgical morbidity in inflammatory bowel disease. Inflamm Bowel Dis 2017;23:1867-72.

[15] Zhang T, Cao L, Cao T, Yang J, Gong J, Zhu W, et al. Prevalence of Sarcopenia and its impact on postoperative outcome in patients with Crohn's disease undergoing bowel resection. JPEN J Parenter Enteral Nutr 2017:41:592-600.

[16] Rocha R, Santana GO, Almeida N, Lyra AC. Analysis of fat and muscle mass in patients with inflammatory bowel disease during remission and active phase. Br J Nutr 2009;101:676-9.

[17] Benjamin J, Makharia G, Ahuja V, Joshi YK. Body composition in Indian patients with Crohn's disease during active and remission phase. Trop Gastroenterol 2011;32:285-91.

[18] Ripoli J, Miszputen SJ, Ambrogini Jr O, Carvalho L. Nutritional follow-up of patients with ulcerative colitis during periods of intestinal inflammatory activity and remission. Arq Gastroenterol 2010;47:49-55.

[19] Geerling BJ, Badart-Smook A, Stockbrugger RW, Brummer RJ. Comprehensive nutritional status in patients with long-standing Crohn disease currently in remission. Am J Clin Nutr 1998;67:919-26.

[20] Valentini L, Schaper L, Buning C, Hengstermann S, Koernicke T, Tillinger W, et al Malnutrition and impaired muscle strength in patients with Crohn's disease and ulcerative colitis in remission. Nutrition 2008;24:694-702.

[21] Geerling BJ, Badart-Smook A, Stockbrugger RW, Brummer RJ. Comprehensive nutritional status in recently diagnosed patients with inflammatory bowel disease compared with population controls. Eur J Clin Nutr 2000;54:514-21.

[22] de Jong MJ, van der Meulen-de Jong AE, Romberg-Camps MJ, Becx MC, Maljaars JP, Cilissen M, et al. Telemedicine for management of inflammatory bowel disease (myIBDcoach): a pragmatic, multicentre, randomised controlled trial. Lancet 2017;390:959-68.

[23] Lennard-Jones JE. Classification of inflammatory bowel disease. Scand J Gastroenterol Suppl 1989;170:2-6, discussion 16-9.

[24] de Jong M, van der Meulen-de Jong A, Romberg-Camps M, Degens J, Becx M, Markus T, et al. Development and feasibility study of a telemedicine tool for all patients with IBD: MyIBDcoach. Inflamm Bowel Dis 2017;23:485-93.
[25] De Jong M, Van den Heuvel T, Romberg-Camps M, Winkens B, Markus T, Masclee A, et al. Development of a patient reported disease activity score to screen for mucosal inflammation in inflammatory bowel disease. J Crohns Colitis 2015;9 S192-3.

[26] de Jong MJ, Roosen D, Degens J, van den Heuvel TRA, Romberg M, Hameeteman W, et al. Development and validation of a patient-reported score to screen for mucosal inflammation in inflammatory bowel disease. J Crohns Colitis 2018.

[27] Kruizenga HM, Seidell JC, de Vet HC, Wierdsma NJ, van Bokhorst-de van der Schueren MA. Development and validation of a hospital screening tool for malnutrition: the short nutritional assessment questionnaire (SNAQ). Clin Nutr 2005:24:75-82.

[28] Neelemaat F, Kruizenga HM, de Vet HC, Seidell JC, Butterman M, van Bokhorstde van der Schueren MA. Screening malnutrition in hospital outpatients. Can the SNAQ malnutrition screening tool also be applied to this population? Clin Nutr 2008;27:439-46.

[29] Cushing KC, Kordbacheh H, Gee MS, Kambadakone A, Ananthakrishnan AN Sarcopenia is a novel predictor of the need for rescue therapy in hospitalized ulcerative colitis patients. J Crohns Colitis 2018.

[30] Holt DQ Varma P, Strauss BJG, Rajadurai AS, Moore GT. Low muscle mass at initiation of anti-TNF therapy for inflammatory bowel disease is associated with early treatment failure: a retrospective analysis. Eur J Clin Nutr 2017:71:773-7.

[31] Gerriets VA, Danzaki K, Kishton RJ, Eisner W, Nichols AG, Saucillo DC, et al. Leptin directly promotes T-cell glycolytic metabolism to drive effector Tcell differentiation in a mouse model of autoimmunity. Eur J Immunol 2016:46:1970-83.

[32] Saucillo DC, Gerriets VA, Sheng J, Rathmell JC, Maciver NJ. Leptin metabolically licenses T cells for activation to link nutrition and immunity. J Immuno 2014;192:136-44.

[33] Cohen S, Danzaki K, Maclver NJ. Nutritional effects on T-cell immunometabolism. Eur J Immunol 2017;47:225-35.

[34] van der Hulst RR, von Meyenfeldt MF, van Kreel BK, Thunnissen FB, Brummer RJ, Arends JW, et al. Gut permeability, intestinal morphology, and nutritional depletion. Nutrition 1998;14:1-6.

[35] Jonkers DM. Microbial perturbations and modulation in conditions associated with malnutrition and malabsorption. Best Pract Res Clin Gastroenterol 2016;30:161-72.

[36] Leistra E, Langius JA, Evers AM, van Bokhorst-de van der Schueren MA, Visser $\mathrm{M}$, de Vet HC, et al. Validity of nutritional screening with MUST and SNAQ in hospital outpatients. Eur J Clin Nutr 2013;67:738-42.

[37] Physical status: the use and interpretation of anthropometry. Report of a WHO Expert Committee. World Health Organ Tech Rep Ser 1995;854:1-452.

[38] Ministerie van Volksgezondheid Welzijn en Sport. Gezondheidsmonitor Volwassenen en Ouderen; 2018 https://www.volksgezondheidenzorg.info/ onderwerp/gezondheidsmonitor-volwassenen-en-ouderen/regionaal.

[39] Csontos AA, Molnar A, Piri Z, Palfi E, Miheller P. Malnutrition risk questionnaire combined with body composition measurement in malnutrition screening in inflammatory bowel disease. Rev Esp Enferm Dig 2017;109:26-32.

[40] Lu ZL, Wang TR, Qiao YQ, Zheng Q, Sun Y, Lu JT, et al. Handgrip strength index predicts nutritional status as a complement to body mass index in Crohn's disease. J Crohns Colitis 2016;10:1395-400.

[41] Cosnes J. Smoking and diet: impact on disease course? Dig Dis 2016;34:72-7.

[42] van den Heuvel TR, Jonkers DM, Jeuring SF, Romberg-Camps MJ, Oostenbrug LE, Zeegers MP, et al. Cohort profile: the inflammatory bowel disease south limburg cohort (IBDSL). Int J Epidemiol 2017;46:e7.

[43] Levine A, Sigall Boneh R, Wine E. Evolving role of diet in the pathogenesis and treatment of inflammatory bowel diseases. Gut 2018;67:1726-38.

[44] Kruizenga HM, Van Tulder MW, Seidell JC, Thijs A, Ader HJ, Van Bokhorst-de van der Schueren MA. Effectiveness and cost-effectiveness of early screening and treatment of malnourished patients. Am J Clin Nutr 2005;82:1082-9.

[45] Satsangi J, Silverberg MS, Vermeire S, Colombel JF. The Montreal classification of inflammatory bowel disease: controversies, consensus, and implications. Gut 2006;55:749-53. 